\title{
Challenge Agent Type Mixed Field Indicator
}

National Cancer Institute

\section{Source}

National Cancer Institute. Challenge Agent Type Mixed Field Indicator. NCI Thesaurus.

Code C158321.

An indication as to whether there is more than one type of ionizing radiation associated with the rad/nuc challenge. 